biopsy in our patients did not show evidence of Crohn's disease, but there was unequivocal evidence of Crohn's disease elsewhere. Furthermore, the failure of symptoms in patients who do not smoke to respond to treatment suggests peptic ulceration associated with Crohn's disease. Treatment with omeprazole led to prompt relief of symptoms and complete healing of ulceration, which was confirmed by endoscopy.

Omeprazole is effective in resistant peptic ulceration, ${ }^{3}$ but there is only one report of its use in Crohn's disease. ${ }^{+} \mathrm{A}$ proton pump inhibitor, it is capable of maintaining high intragastric $\mathrm{pH}$ for long periods. ${ }^{5}$ Its effectiveness in our two patients suggests that duodenal ulceration in Crohn's disease is dependent on acid. If prolonged active ulceration can cause pyloric stenosis then intermittent omeprazole treatment might prevent this complication in patients with Crohn's disease. Our observations support the view that inhibition of acid production is more likely to heal duodenal ulceration associated with Crohn's disease than steroid treatment, which may lead to complications such as perforation or haemorrhage.

1 Weterman IT. Oral, oesophageal and gastro-duodenal Crohn's disease. In: Allan RN, Keighley MRB, Alexander-Williams J, Hawkins C, eds. Intan RN, Keighy 299-306.

2 Fielding JF, Cooke Wr. Peptic ulceration in Crohn's disease regional enteritis Gut 1970;11:998-1000.

3 Tỵtgat GNJ. Lamers CBHW, Hameeteman W, Jansen JMB, Wilson JA. Omeprazole in peptic ulcers resistant to histamine $\mathrm{H}_{2}$-receptor antagonists. Alimentary Pharmacologv and Therapeutics 1987;1:31-8.

+ Woolfson K. Greenberg GR. Symptomatic improvement of gastroduodenal Crohn's disease with omeprazole [Abstract]. Gastroenterology 1989;96:A551. Walt RP, Gomes MDFA, Wood EC, Logan LH, Pounder RE. Effect of daily oral omeprazole on 24 hour intragastric acidity. Br. Hed f 1983;287:12-t.

Accepled 28. Vorember 1989)

\section{Detection of pseudodiarrhoea by simple clinical assessment of intestinal transit rate}

\author{
Luke J D O'Donnell, Jim Virjee, \\ Kenneth W Heaton
}

Departments of Medicine and Radiology, Bristol Royal Infirmary, Bristol BS2 8HW

Luke J D O'Donnell, MD, medical registrar

Jim Virjee, FRCR, consultant radiologist

Kenneth W Heaton, FRCP, reader in medicine

Correspondence to:

Dr Heaton.

Br.Med f 1990;300:439-40

Many patients with the irritable bowel syndrome have frequent and urgent defecation that they describe as diarrhoea. Frequency and urgency can be due to an irritable rectum, as in ulcerative proctitis, ${ }^{\prime}$ and patients with these complaints mav have normal gut transit times. These patients might be said to have "pseudodiarrhoea" (faecal frequency without diarrhoea). True diarrhoea entails rapid transit through the intestine, but transit time is not measured routinely in clinics and until recently there were no accurate ways of doing so. ${ }^{2}{ }^{3}$ As different treatments are appropriate for patients with fast, normal, and slow transit a simple method of measuring transit in the outpatient clinic would be valuable. Davies $e t$ al found a close correlation between whole gut transit time and stool form scored on an eight point scale, but they studied motivated volunteers and a scientific observer examined the stools. ${ }^{+} \mathrm{We}$ investigated whether a simple record of stool form kept by the patient could be used as a guide to intestinal transit rate in the irritable bowel syndrome.

\section{Patients, methods, and results}

We devised a seven point scale in which stools were scored according to cohesion and surface cracking: 1 , separate hard lumps like nuts; 2 , sausage shaped but lumpy; 3 , like a sausage or snake but with cracks on its surface; 4 , like a sausage or snake, smooth and soft; 5 , soft blobs with clear cut edges; 6 , fluffy pieces with ragged edges, a mushy stool; 7 , watery, no solid pieces.

We recruited 30 consecutive patients ( 10 men, 20 women; ages 18-68) from a general gastroenterology outpatient department. All fulfilled the diagnostic criteria for the irritable bowel syndrome ${ }^{5}$ and consented to the study. Each patient was given a form to record the type and time of evacuation of six consecutive stools and to indicate whether the desire to defecate was urgent. The mean score for the six defecations was calculated for each patient. Whole gut and regional colonic transit times were measured simultaneously: patients swallowed 20 radio-opaque polyethylene markers on four consecutive mornings, and an abdominal radiograph was obtained on the fifth morning. Whole gut transit time was calculated as $1 \cdot 2$ times the number of markers in the abdomen and regional transit time as 1.2 times the number of markers in the region. ${ }^{3}$ In one patient with slow transit radiography was repeated on the sixth morning.

Whole gut transit time ranged from six to 108 hours. Stool frequency ranged from $0 \cdot 3$ to $5 \cdot 0 / 24 \mathrm{~h}$. There was no relation between stool frequency and whole gut transit time $(r=-0.022)$. The mean stool form score was evenly distributed, with similar numbers of patients scoring $<3,3-5$, and $>5$. Mean stool form score correlated well with whole gut transit time $(\mathrm{r}=-0.77, \mathrm{p}<0.001$; figure). Although there were

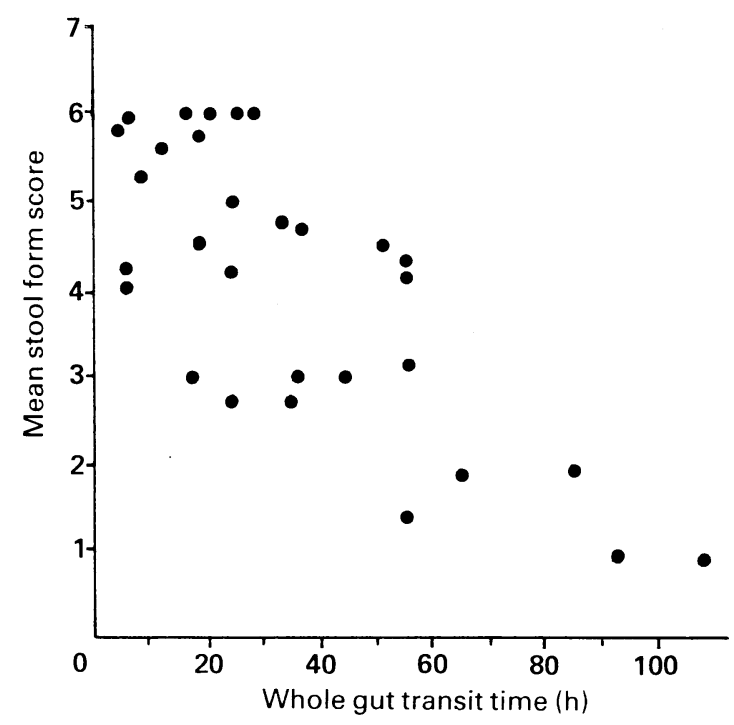

Relation between mean stool form score ( $1=$ hard lumps, $7=$ watery; see text) and whole gut transit time in patients with irritable bowel syndrome $(r=-0.77, p<0 \cdot 001)$

significant correlations between regional colonic transit time and mean stool form score, no area of the colon was particularly associated with stool form (right colon, $\mathrm{r}=-0.43, \mathrm{p}<0.05$; left colon, $\mathrm{r}=-0.62$, $\mathrm{p}<0.01$; sigmoid and rectum, $\mathrm{r}=-0.54, \mathrm{p}<0.01$ ). Urgency was recorded at least once by 22 patients. Urgency was associated with looser stools $\left(\chi^{2}\right.$ for trend $=26, \mathrm{df}=1, \mathrm{p}<0.001$ ), but the frequency of defecation was the same in patients with and without urgency (median frequency $=1.6 v 1.9 / 24 \mathrm{~h} ; \mathrm{p}=0.8$, Mann-Whitney U test).

\section{Comment}

We found that patients with the irritable bowel syndrome can keep meaningful records of stool form and that these are a reasonable guide to whole gut 
transit time. In patients with formed stools (scores 1-4) and normal or slow transit frequent defecation and urgency are actually pseudodiarrhoea, presumably due to an irritable or hyperreactive rectum, and constipating agents should be avoided. As patients with slow and fast transit may respond differently to high fibre diets and bulking agents, respectively, perhaps they should be asked to record their stool form so that the doctor can assess the transit rate and plan treatment.
1 Rao SSC, Holdsworth CD, Read NW. Symptoms and stool patterns in patients with ulcerative colitis. Gut 1988;29:342-5.

Cummings JH, Wiggins HS. Transit through the gut measured by analysis of a single stool. Gut 1976;17:219-23.

Metcalfe AM, Phillips SF, Zinsmeister AR, MacCarthy RL, Beart RW, Wolff BG. Simplified assessment of segmental colonic transit. Gastroenterology 1987;92:40-7.

4 Davies GJ, Crowder M, Reid B, Dickerson JWT. Bowel function measurements of individuals with different eating patterns. Gut 1986;27:164-9.

5 Manning AP, Thompson WG, Heaton KW, Morris AF. Towards positive diagnosis of the irritable bowel. Br Med F 1978;ii:653-4.

(Accepted 17 October 1989)

\section{Anxiety caused by abnormal result of cervical smear test: a controlled trial}

\author{
Clare Wilkinson, Jane M Jones, Jenny McBride
}

Department of General Practice, University of Wales College of Medicine, Cardiff CF3 7PN Clare Wilkinson, MRCGP, lecturer

\section{South Glamorgan Health Authority, Cervical Cytology Clinic, St David's Hospital, Cardiff CF1 9TZ Jane $M$ Jones, FRCOG, director of the cervical cytology programme}

\section{Department of Clinical Psychology, University Hospital of Wales, Cardiff CF4 4XW \\ Jenny McBride, DIPCLINPSYCH,} senior clinical psychologist

Correspondence to: Dr C Wilkinson, Llanedeyrn Health Centre, Maelfa, Cardiff CF3 7PN.
Cervical intraepithelial neoplasia is common in young symptomless women. Such women often believe that the function of a smear test is to detect cancer rather than to prevent it. ${ }^{1}$ Insensitive postal notification of abnormal results can cause unnecessary fear and add to the negative aspects of a mass screening programme. ${ }^{23}$

We carried out a controlled trial to assess women's anxiety and beliefs about their health when a smear test showed dyskaryosis and to evaluate the effectiveness of a personal leaflet sent with postal notification of the result of such a test.

\section{Patients, methods, and results}

Women due to attend the University Hospital of Wales because a cervical smear test had shown dyskaryosis were randomly assigned to one of two groups. The first group (31 patients) received a standard computerised letter, which read: "Your recent smear test showed slight abnormality. Please could you attend the cytology clinic at...for a repeat test and further advice." The second group (29 patients) received a leaflet and a more personalised letter stating, "Your recent smear test showed slight abnormality which need cause you no anxiety. Please read the enclosed leaflet carefully, you will find it helpful and reassuring. Please could you attend the cytology clinic at ... on. ..." The main message in the leaflet was that most smears showing dyskaryosis do not indicate cervical cancer. All patients were interviewed during the consultation by the examining doctor $(\mathrm{CW})$, who used a structured questionnaire. Information collected comprised sociodemographic data, psychiatric history, the women's perceptions of the meaning of the result of their smear test, and their perceptions of their health after receiving the result. They were asked who they had chosen to discuss the result with and whether they had sought professional advice before their appointment. Differences between the two groups were measured by comparing the women's beliefs about their health as measured by the questionnaire and their levels of anxiety before and after consultation as assessed with the Speilberger state-trait anxiety inventory. ${ }^{+}$

Nineteen women who did not receive a leaflet thought that they had cancer compared with only one of the women who did receive a leaflet $\left(\chi^{2}=22 \cdot 56, \mathrm{df}=\right.$ $1, p<0.001)$. Twelve of the women not sent a leaflet thought that their health had deteriorated on receipt of the result compared with two who were sent a leaflet $(\mathrm{p}<0.01$; Wilcoxon matched pairs signed ranks test).
The group who were not sent a leaflet had a significantly higher initial state anxiety level than the group who were $(\mathrm{p}<0.0001)$. State anxiety levels after consultation and trait anxiety levels were not significantly different between the groups (table).

Anxiety scores of patients who had received letter, with or without reassuring leaflet, informing them that cervical smear test showed dyskaryosis

\begin{tabular}{lccc}
\hline $\begin{array}{c}\text { Mean Speilberger } \\
\text { state-trait inventory } \\
\text { scores (scale 20-80) }\end{array}$ & $\begin{array}{c}\text { Group not } \\
\text { sent leaflet } \\
(\mathrm{n}=31)\end{array}$ & $\begin{array}{c}\text { Group } \\
\text { sent leaflet } \\
(\mathrm{n}=29)\end{array}$ & $\begin{array}{c}\text { Difference between } \\
\text { means }(95 \% \\
\text { confidence interval) }\end{array}$ \\
\hline State anxiety levels: & & & \\
Before consultation & 49.59 & $39 \cdot 00$ & $10.59(5 \cdot 8$ to $14 \cdot 8)$ \\
After consultation & 33.35 & 32.21 & $1.14(-3.4$ to $5 \cdot 7)$ \\
Trait anxiety levelf & 40.81 & 37.21 & $3.60(-7.6$ to 0.4$)$
\end{tabular}

* State anxiety is a measure of transitory emotional state characterised by subjective feelings of tension and heightened autonomic nervous system activity.

+ Trait anxiety is a measure of relatively stable individual differences in anxiety proneness.

\section{Comment}

Our study highlights the fact that precancer is a concept that women find difficult to understand. The term implies early cancer to most women, and a new term-for example, "early warning cells"-would seem more appropriate. The mean level of anxiety before consultation in the women not sent a leaflet was similar to that provoked by very stressful situations, while the mean in the group sent a leaflet was similar to that expected for general medical and surgical outpatients. ${ }^{5}$

Evidence suggests that investigation and treatment of cervical intraepithelial neoplasia is psychologically traumatic. ${ }^{5}$ Good education and counselling from the onset may prevent future psychiatric and psychological morbidity and improve compliance with treatment. A questionnaire sent to all health authorities in Wales in September 1988 showed that, although seven of nine health authorities sent educational leaflets with cervical cytology call and recall letters, only one sent leaflets when notifying women of normal or abnormal results of smear tests. Our study suggests that these leaflets should be sent with notification of abnormal results.

We thank Professor Nigel Stott and Dr Roisin Pill, department of general practice, University of Wales College of Medicine, and Dr Tim Peters, department of medical statistics, University Hospital of Wales, for help with design and analysis; Mrs Penny Moore for typing the manuscript; and Pfizer for financial help.

\footnotetext{
1 Eardley A. Attendance for cervical screening-whose problem? Soc Sci Med 1985;20:955-62.

2 McCormick J. Cervical smears: a questionable practice? Lancet 1989;ii:207-9. 3 Marteau T. Psychological costs of screening. Br Med f 1989;299:527.

4 Speilberger C. Manual for the state-trait anxiety inventory. California: Consulting Psycher C. Manual for the sid

5 Posner T, Vessey M. Prevention of cervical cancer-the woman's view. Oxford: Nuffield Provincial Hospitals Trust, 1988.

(Accepted 29 November 1989)
} 